\title{
An Empirical Study of Learning Outcomes Based on Active Versus Passive Teaching Styles
}

\author{
Ying Cui ${ }^{\text {a, }}$ \\ ${ }^{a}$ Hohai University, Nanjing, China,210098 \\ ${ }^{b}$ Henan University of Technology, Zhengzhou, China, 450001
}

\begin{abstract}
This paper compares the impact of an active teaching approach and a passive teaching style on student cognitive outcomes. Through two sections of an introductory Management course, one part was taught in an active manner, with a variety of active learning exercises. The other was taught in a passive way, emphasizing daily lectures. Across the empirical study, we conclude that active learning can improved cognitive outcomes in class-specific materials.
\end{abstract}

Index Terms: Active Teaching; Passive Teaching; Cognitive Outcomes; Empirical Study

(C) 2013 Published by MECS Publisher. Selection and/or peer review under responsibility of the International Conference on E-Business System and Education Technology

\section{INTRODUCTION}

Because of increasing competitive demands in the world, management educators strive to provide the most productive classroom experience for their students in order to prepare them for careers in the business world. To achieve this objective, management educators constantly search for new and improved teaching methods. The main purpose of the present study is to compare the impact of an active teaching approach and a traditional or passive teaching style on student cognitive outcomes.

\section{BASCIC DEFINITIONS}

Active Learning. Active learning described several models of instruction that hold learners responsible for their own learning. For example, students engage in "doing things and thinking about what they are doing" in the classroom.

Passive Learning. Passive learning is prevalent in the traditional teaching approach taken by many professors in business schools. These professors deliver lectures for majority time and there is little opportunity for student input through discussion or experiential exercises.

\footnotetext{
* Corresponding author:

E-mail address: cuiyingbaby@126.com
} 


\section{STUTY DESIGN}

\section{Theoretical Assumptions}

H1Broad student learning outcomes are stronger in active teaching contexts than passive ones.

H2Class-specific learning outcomes are stronger in active teaching contexts than passive ones.

\section{Samples}

The goal of our research was to test whether active learning methods, compared to passive learning methods, can improve cognitive outcomes of students. The study was undertaken at Management School at a regional university in Henan province in China with an enrollment of approximately 300students. Nearly 100\%of the university's students attend full-time, $18 \%$ of first-time students receive some type of financial aid, $78 \%$ of all undergraduates studied science before, and 25\% of undergraduates are planning to receive higher level education. We conducted our study in two sections of an Introduction to Management class, each taught by a different teaching style, during one semester course.

\section{IV. EMPIRICAL PROCESS}

Random Assignment. As with any experimental study of this nature. One problem is that students were not randomly assigned to the two sections of the course. This lack of random assignment would be most problematic if students registered for either section knowing that it would be taught by one particular method.

Demographic Issues. Table 1 presents basic summary statistics for each section of course and shows that students in the traditional class had lower final and core assessment grades. The core assessment grades consist of only quiz averages for the active section, and only exam averages for the traditional class. In both the traditional and active classes, all cognitive outcome assessments consisted of multiple-choice/ true-false questions that were machine graded.

TABLE 1 DESCRIPTIVE STATISTICS OF STUDENTS SAMPLED

\begin{tabular}{|l|l|l|l|l|l|l|l|l|}
\hline \multirow{2}{*}{ Measures } & \multicolumn{3}{|c|}{ Traditional Teaching Style Class } & \multicolumn{4}{c|}{ Active Teaching Style Class } \\
\cline { 2 - 10 } & Mean & Median & SD & $\%$ & Mean & Median & SD & $\%$ \\
\hline HSGPA & 2.47 & 2.82 & 1.25 & -- & 2.89 & 3.31 & 1.04 & -- \\
\hline CCT & 17.45 & 18.5 & 8.6 & -- & 19.66 & 20.85 & 4.83 & -- \\
\hline Age & 19.79 & 19 & 6.77 & -- & 18.62 & 18 & 3.58 & -- \\
\hline Final grade & 76.7 & 77 & 10.39 & -- & 84.35 & 86.32 & 8.32 & -- \\
\hline Core assessment & 75.87 & 76.5 & 9.9 & -- & 74.74 & 81.9 & 19.47 & -- \\
\hline Absent & 15.63 & 16.64 & 11.5 & -- & 17.41 & 8.1 & 22.94 & -- \\
\hline Female & -- & -- & -- & 0.37 & -- & -- & -- & 0.45 \\
\hline Withdrew & -- & -- & -- & 0.10 & -- & -- & -- & 0.08 \\
\hline
\end{tabular}

Note: HSGPA=high school grade point average; $\mathrm{CCT}=$ Chinese College Testing composite score;

Core Assessment=average scores for all quizzes and exams; Absent=percentage of classes missed; Withdrew =percentage of students that formally withdrew from the class; $\mathrm{SD}=$ standard deviation.

Student Withdrawal Range restriction challenges our analysis in that withdrawing students are left out of the final sample. Because student attrition has been shown to bias ordinary least squares estimators, we use the propensity score approach to account for the likelihood students will withdraw from a class. Then the propensity for dropping the course is estimated with a probit equation and then included as an independent 
variable in the main regression.

Analysis Probit and OLS equations are provided in the following analysis.

$$
\begin{aligned}
\text { Withdraw }= & \alpha+\beta_{1} \text { Gender }+\beta_{2} \text { Age }+\beta_{3} H S G P A+\beta_{4} C C T \\
& +\beta_{5} E C C T+\beta_{6} \text { Absent }+e .
\end{aligned}
$$

In the probit model, Withdraw is the student's binary choice of dropping the course through formal withdrawal (set to 1 for withdrawal and 0 for remaining enrolled), Gender is set to 1 for males, Age is the student's age in years, HSGPA, CCT and absent are follow with Table 1, ECCT is the student's score on the English portion of the CCT. The strongest predictor of whether students would withdraw from the class is the variable for the percentage of classes missed.

Each student's predicted probability of withdrawing is then included in main regressions. Our main OLS equation is as follow:

TABLE 2 Probit Equation Results to Control for Bias Caused by Student Withdrawal

\begin{tabular}{|c|c|c|}
\hline Independent Variables & Coefficient & SE \\
\hline Gender & 0.49 & 0.73 \\
\hline Age & -0.02 & 0.05 \\
\hline HSGPA & 0.22 & 0.41 \\
\hline CCT & 0.23 & 0.18 \\
\hline English & -0.33 & 0.21 \\
\hline Absent & $3.76^{* *}$ & 1.72 \\
\hline Constant & -2.01 & 1.27 \\
\hline Pseudo R2 & & \\
\hline $\mathrm{N}$ & & 0.28 \\
\hline
\end{tabular}

Note: Table 2 presents results from the probit model where Withdr is the predicted outcome and is set to 1 for withdrawal. In the results columns, coefficient indicates the parameter estimate, SE indicates the standard error, and statistical significance is identified as follows: ${ }^{* *} \mathrm{p}<0.01, * * \mathrm{p}<0.05,{ }^{*} \mathrm{p}<0.1$.

$$
\begin{aligned}
\text { ExamScore }= & \alpha+\beta_{1} \text { GrLev }+\beta_{2} H S G P A+\beta_{3} \text { Pr } i v+\beta_{4} C C T \\
& +\beta_{5} \text { Gender }+\beta_{6} \text { Age }+\beta_{7} \text { Absent }+\beta_{8} \text { SectionID } \\
& +\beta_{9} p-\text { hat }+e .
\end{aligned}
$$

(2) The p-hat is the propensity score from the probit model, the section ID, is an indicator variable set to 1 for students in the active course and 0 for those in the traditional course, and it represents the marginal difference in the cognitive outcome for students in the active section. The remaining independent variables are as follow Table 2.Table 3 highlights summary statistics related to our cognitive outcome measures. These statistics show that when students were assessed on only their respective teacher's questions, the active students scored approximately 4 percentage points higher than the traditional students at both the mean and median. This finding could indicate that active learning improved cognitive outcomes, but these are strictly univariate measures.

A total of 12 questions were eliminated from the exam, of which 7 were contributed by the traditional teacher and 5 by the active teacher. These results show, at the mean, students in both sections performed nearly the same on the 38 common-question exam (75.9 in the traditional section vs. 75.4 in the active section). At the median, the active section scored slightly better than students in the traditional section (78 vs. 74), indicating a more skewed left distribution in the active section. Because of this finding, we use both OLS and median 
regression for our main hypothesis tests.

The first set of results from running model (2) is presented in Table 4. The variable of interest is the estimated coefficient on Section ID, which estimates the marginal difference in the cognitive outcome for students in the active section. Because the dependent variable is the score on the 38 common-question exam, the cognitive measure represents how well students learned the broad subject matter taught in the typical Introduction to Management class. In other words, we are testing H1. The first column of results shows that the OLS point estimate for the coefficient on Section ID is -0.69 , with a standard error of 1.52 . In this case, there is no significant difference across the two sections. Therefore, H1 is not supported by these results. In regards to the broad subject area of the course, there is no significant difference between student learning outcomes of those exposed to the active and passive teaching approaches.

Table 5 indicates that active learning had a positive impact on cognitive outcomes. For instance, with the use of OLS, the estimated coefficient on Section ID is 4.13, with a standard error of 2.22. Although not statistically significant at the 5\% level of significance, this estimate is significant at the $10 \%$ level (the p-value is 0.065).This median estimate indicates that students in the active section scored almost 8.5 points higher on "their" 25 questions than students in the traditional section scored on Therefore, if we focus on how well students learned the specific material taught in their section of the course, students in the active learning section outperformed their counterparts by, on average, nearly an entire letter grade. These findings support Hypothesis

\section{TABLE 3 SUMMARY STATISTICS FOR LEARNING OUTCOMES}

\begin{tabular}{|l|c|c|c|c|c|c|c|c|}
\hline \multirow{2}{*}{ Learning Outcome } & \multicolumn{4}{|c|}{ Traditional Teaching Style } & \multicolumn{4}{c|}{ Active Teaching Style } \\
\cline { 2 - 10 } & Mean & Median & SD & $\mathrm{n}$ & Mean & Median & SD & $\mathrm{n}$ \\
\hline Class-specific learning & 66.45 & 69.00 & 12.63 & 106 & 72.17 & 73.00 & 19.87 & 116 \\
\hline Broad learning outcomes & 75.90 & 74.00 & 11.23 & 106 & 75.40 & 78.00 & 13.29 & 116 \\
\hline Fifty-question outcomes & 64.41 & 64.00 & 12.92 & 106 & 57.64 & 58.00 & 14.83 & 116 \\
\hline
\end{tabular}

Note: Class-specific learning reports students' percentage of correct answers on questions only related to their class. Broad learning outcomes reports scores on the 38 -question common test.

\section{CONCLUSION}

In conclusion, our study contributes to the management education literature with quantitative evidence that the active teaching approach may have a greater positive influence on student learning than the passive teaching approach in some contexts. Our results show higher student cognitive outcomes on specific material covered in a class taught with the active learning approach as opposed to one taught with the passive teaching approach.

\section{ACKNOWLEDGMENT}

This research was supported in part by the founding from the Soft Science Project (102400440010) (82400440500) 
TABLE 4 REGRESSION RESULTS : BROAD COGNITIVE LEARNING OUTCOMES

\begin{tabular}{|c|c|c|c|c|}
\hline \multirow{2}{*}{ Independent Variables } & \multicolumn{2}{|c|}{ OLS Regression } & \multicolumn{2}{c|}{${\text { Median Re } \text { gression }^{a}}^{*}$} \\
\cline { 2 - 5 } & Coefficient & SE & Coefficient & SE \\
\hline GrLev & $2.51^{*}$ & 1.42 & 2.24 & 1.59 \\
\hline HSGPA & $2.55^{*}$ & 1.47 & 1.28 & 1.46 \\
\hline CCT & $0.60^{* *}$ & 0.25 & $0.97 * * *$ & 0.24 \\
\hline Gender & 0.41 & 1.48 & 0.92 & 1.78 \\
\hline Age & $1.07^{* * *}$ & 0.25 & $1.23^{* * *}$ & 0.29 \\
\hline Absent & -9.84 & 8.11 & -6.01 & 9.04 \\
\hline SectionID & -0.69 & 1.52 & 2.48 & 1.85 \\
\hline p-hat & 30.63 & 33.35 & 9.48 & 31.63 \\
\hline Intercept & $32.4 * * *$ & 8.81 & $24.7 * * *$ & 8.94 \\
\hline $\mathrm{N}$ & \multicolumn{2}{|c|}{178} & & 178 \\
\hline
\end{tabular}

Note: Table 4 presents results from running model (2) with the measure for broad student learning outcomes as the dependent variab. Rresult from rerunning Model 2 with median regression.

TABLE 5 REGRESSION RESULTS: SPECFIC LEARNING COGNITIVE OUTCOMES

\begin{tabular}{|c|c|c|c|c|}
\hline \multirow{2}{*}{ Independent Variables } & \multicolumn{2}{|c|}{ OLS Regression } & \multicolumn{2}{|c|}{ Median $^{2}$ Re $^{2}$} \\
\cline { 2 - 5 } & Coefficient & SE & Coefficient & SE \\
\hline GrLev & 1.68 & 1.78 & 2.34 & 2.56 \\
\hline HSGPA & 3.25 & 1.97 & 1.42 & 2.26 \\
\hline CCT & $0.80^{* *}$ & 0.35 & $1.08^{* * *}$ & 0.34 \\
\hline Gender & -0.16 & 2.18 & 1.52 & 2.78 \\
\hline Age & $1.67^{* * *}$ & 0.35 & $1.43^{* * *}$ & 0.43 \\
\hline Absent & -11.84 & 9.11 & -13.01 & 12.04 \\
\hline SectionID & $4.13^{*}$ & 2.22 & $8.43^{* * *}$ & 2.85 \\
\hline p-hat & 33.63 & 43.35 & -5.84 & 41.63 \\
\hline Intercept & 7.43 & 10.81 & 8.63 & 13.94 \\
\hline $\mathrm{N}$ & \multicolumn{2}{|c|}{178} \\
\hline
\end{tabular}

Note: Table 5 presents results from running model (2) with the measure for broad student learning outcomes (the exam scores on the 38 common-question exam) as the dependent variable. The independent variables are as follow Table 4.

\section{REFERENCES}

[1] Myers, C. B., \& Myers, S. M. (2007). Assessing assessment: The effects of two exam formats on course achievement and evaluation. Innovative Higher Education, 31, 227-236.

[2] Jones, A. C. (2008). The effect of out-of-class support on student satisfaction and motivation to learn. Communication Education, 57, 373-388.

[3] Auster, E. R., \& Wylie, K. K. (2006). Creating active learning in the classroom: A systematic approach. Journal of Management Education, 30, 333-354. 